\title{
The legacy of Southern American extinct megafauna on plants and biomes biomes
}

\author{
Vinícius Dantas ${ }^{1}$ and Juli Pausas ${ }^{2}$ \\ ${ }^{1}$ Universidade Federal de Uberlandia \\ ${ }^{2}$ Centro de Investigaciones sobre Desertificacion
}

December 4, 2020

\begin{abstract}
Large mammal herbivores are important drivers of plant evolution and vegetation patterns, but whether current plant traits and ecosystem geography reflect the historical distribution of extinct megafauna is unknown. We address this question for Southern America (Neotropical biogeographic realm) by relating plant defense trait information at the ecoregion scale to climate, soil, fire, and the historical distribution of megafauna. Here we show that megafauna history explains substantial trait variability and detected three distinct regions (called "Antiherbiomes") characterized by convergent plant defense strategies, environmental and megafauna patterns. We also identified ecoregions that experienced biome shift, from grassy- to forest- dominated, following the Pleistocene megafauna extinction. These results suggest that extinct megafauna left a significant imprint in the current plant trait and ecosystems biogeography of Southern America.
\end{abstract}

\section{Hosted file}

f1d58bb1220f6b3ad6aeadb11358c01bf4fe721c.pdf available at https://authorea.com/users/363315/ articles/484117-the-legacy-of-southern-american-extinct-megaf auna-on-plants-and-biomes 